\title{
Use of azathioprine for graft-vs-host disease is the major risk for development of secondary malignancies after haematopoietic stem cell transplantation: a nationwide population-based study
}

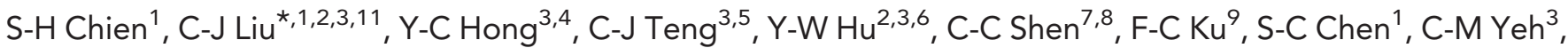
T-J Chiou ${ }^{3,10}$, J-P Gau ${ }^{*, 1,3,11}$ and C-H Tzeng ${ }^{1,3}$

${ }^{1}$ Division of Hematology and Oncology, Department of Medicine, Taipei Veterans General Hospital, No. 201, Shipai Road, Section 2, Taipei 11217, Taiwan; ${ }^{2}$ Institute of Public Health, National Yang-Ming University, Taipei, Taiwan; ${ }^{3}$ School of Medicine, National Yang-Ming University, Taipei, Taiwan; ${ }^{4}$ Division of Hematology and Oncology, Department of Medicine, Kaohsiung Veterans General Hospital, Kaohsiung, Taiwan; ${ }^{5}$ Division of Oncology and Heamtology, Department of Medicine, Far Eastern Memorial Hospital, Taipei, Taiwan; ${ }^{6}$ Cancer Center, Taipei Veterans General Hospital, Taipei, Taiwan; ${ }^{7}$ Department of Psychiatry, Chiayi Branch, Taichung Veterans General Hospital, Chiayi, Taiwan; ${ }^{8}$ Department of information management, National Chung-Cheng University, Chiayi, Taiwan; ${ }^{9}$ Department of Hematology and Oncology, Show Chwan Memorial Hospital, Changhua, Taiwan and ${ }^{10}$ Division of Transfusion Medicine, Department of Medicine, Taipei Veterans General Hospital, Taipei, Taiwan

Background: As more patients are treated by haematopoietic stem cell transplantation (HSCT), development of secondary malignancy (SM) becomes an increasingly common issue in long-term survivors.

Methods: We conducted a nationwide population-based study of the Taiwanese population to analyse patients who received HSCT between January 1997 and December 2010. Standardised incidence ratios (SIRs) were used to compare the risk of SM in HSCT patients and the general population. Multivariate analysis was performed to identify independent predictors of SM.

Results: Patients receiving HSCT had a significantly greater risk of developing SM (SIR 2.00; 95\% confidence interval (CI) 1.45-2.69; $P<0.001$ ). Specifically, the incidence increased for cancers of the oral cavity (SIR 14.18) and oesophagus (SIR 14.75) after allogeneic HSCT. Multivariate analysis revealed an increased SIR for cancer in patients who received the immunosuppressant azathioprine. The risk of SM also increased with greater cumulative doses of azathioprine.

Conclusions: This study demonstrates an increased incidence of SM in Taiwanese patients who received allogeneic HSCT, especially for cancers of the oral cavity and oesophagus. This finding is different from results in populations of Western countries. Physicians should be cautious about azathioprine use for graft-vs-host disease after HSCT.

*Correspondence: Dr J-P Gau; E-mail: jpgau@vghtpe.gov.tw or Dr C-J Liu; E-mail: chiajenliu@gmail.com

${ }^{11} \mathrm{~J}-\mathrm{P}$ Gau and C-J Liu share co-corresponding authorship.

Received 3 June 2014; revised 1 September 2014; accepted 7 September 2014; published online 14 October 2014

(c) 2015 Cancer Research UK. All rights reserved 0007-0920/15 
Since 1983, haematopoietic stem cell transplantation (HSCT) has been widely used to treat and cure many malignant and benign haematological diseases in Taiwan (Chen et al, 2008). Although the overall survival after transplantation has gradually improved, important concerns remain regarding long-term complications of HSCT, such as secondary malignancy (SM), chronic graft-vs-host disease (cGVHD), infertility, and quality of life (La Nasa et al, 2013). Recently, the development of SM has become a serious complication resulting in substantial mortality (Yokota et al, 2012).

Many studies conducted in Western countries have reported that HSCT increases the risk of SM, especially in patients receiving total body irradiation (TBI) or immunosuppressants and in patients with cGVHD (Curtis et al, 1997, 2005; Rizzo et al, 2009; Majhail, 2011; Majhail et al, 2011). However, few studies have examined SM after HSCT in Asian populations. Moreover, the reported incidences and subtypes of secondary cancers are different from those reported in Western countries (Shimada et al, 2005; Yokota et al, 2012). To explore this issue in Taiwan, we conducted a nationwide population-based study using data from Taiwan's National Health Insurance (NHI) Research Database (NHIRD) to determine the incidence of SM after HSCT in the Taiwanese population.

\section{MATERIALS AND METHODS}

Data sources. Taiwan's NHI is a mandatory universal health insurance programme that was established in 1995 to provide comprehensive medical care coverage for $>99 \%$ of Taiwanese residents (Wu et al, 2012). The NHI covers prescription medications and outpatient, inpatient, emergency, and surgical services. The database includes enrollment files, prescription information, and coding for major procedures. This study is mainly based on data from the NHIRD, which is managed and publicly released by the National Health Research Institute (NHRI) of Taiwan.

In Taiwan, patients who receive HSCT or have malignant diseases are classified in the 'Catastrophic Illness' group and maintained in a separate NHRI database (Catastrophic Illness Registry). Assignment to the Catastrophic Illness classification requires a definitive diagnosis based on pathological findings or clinical evidence that is widely accepted as sufficient to make a diagnosis. Confidentiality of data is managed and overseen by regulators of the Bureau of the NHI and the NHRI. This study was approved by the institutional review board of the Taipei Veterans General Hospital (2013-10-002CE).

Identification of patients receiving HSCT. We conducted a retrospective cohort study from 1 January 1997 to 31 December 2010. We identified patients who received a first course of HSCT within the observation period based on the reimbursement for HSCT. To avoid confusion between primary malignancies treated by HSCT and SMs after HSCT, we only included patients receiving HSCT for haematologic malignancies, thalassaemia major, or severe aplastic anaemia. Patients receiving HSCT for solid organ cancers or immune deficiencies, metabolic disorders, or other congenital diseases were excluded. To avoid surveillance bias (Bilimoria et al, 2013; Chiolero et al, 2013), patients who developed cancers within 1 year after HSCT, as well as those who were followed for $<1$ year after HSCT were excluded. The following information was collected for all patients: basic data, comorbidities, primary diagnosis before HSCT, transplantation type (e.g., allogeneic HSCT (allo-HSCT) or autologous HSCT (auto-HSCT)), TBI, use of immunosuppressive agents, and cGVHD status. A diagnosis of cGVHD was made by an experienced haematologist who reviewed data regarding patterns of immunosuppressant use.
Statistical analyses. The main dependent variable was the occurrence of solid organ cancers that were recorded in the Catastrophic Illness Registry. Patients were followed until the development of solid cancer, death, dropout from the NHI programme, or the end of 2011. Risk of SM in the HSCT cohort was calculated as the standardised incidence ratio (SIR), defined as the observed number of SM occurrence divided by the expected number of cases. The expected number was determined by multiplying the national incidence rate (in 5-year intervals) of same cancers stratified by gender, calendar year, and age, by the corresponding stratum-specific person-time accrued in this cohort. Incidence rates of cancers in the general population were obtained from the Taiwan Cancer Registry. The 95\% confidence intervals (CIs) for the SIRs were estimated under the assumption that the number of cancers followed a Poisson probability distribution. We determined the SIRs for subgroups defined by age at HSCT, sex, follow-up time since HSCT, and stem cell type. In addition, the SIR was estimated for each SM subtype.

Physical comorbidities before HSCT, immunosuppressant use, and cGVHD development were analysed to determine hazard ratios for SM. Categorical variables were compared by Fisher's exact or chi-square tests. Continuous variables were compared with the Mann-Whitney $U$-test. Univariate and multivariate Cox proportional hazards models were utilised to identify predictors of SM in HSCT patients. All factors with a $P$-value of $<0.1$ in the univariate analyses were included in the Cox multivariate analysis. Effects of immunosuppressant use after HSCT were treated as time-dependent variables to prevent an immortal time bias. Furthermore, if one type of immunosuppressant had a significant effect on SM in the Cox multivariate model, the effects of cumulative doses were estimated by time-dependent Cox proportional hazards models using cutoff points at non-use and the 50th percentile.

Data extraction and computations were performed with the Perl programming language (version 5.12.2; Perl Foundation, Walnut, CA, USA). Microsoft SQL Server 2005 (Microsoft Corp., Redmond, WA, USA) was used for data linkage, processing, and sampling. All statistical analyses were performed with the SAS 9.2 software (SAS Institute Inc., Cary, NC, USA). Statistical significance was defined as a $P$-value of $<0.05$.

\section{RESULTS}

Clinical characteristics of the study population. A total of 4014 patients who received HSCT between 1997 and 2010 were identified. After excluding patients who were treated with HSCT for metabolic disorders, severe combined immunodeficiency, or solid cancers $(n=230)$, who had solid cancer before HSCT $(n=112)$, who had $<1$ year of follow-up $(n=1122)$, and who developed secondary solid cancer within 1 year after HSCT $(n=6)$, a total of 2544 patients met eligibility criteria and were enrolled in the study (Supplementary Figure 1). Patient demographics are detailed in Table 1 . Study subjects were predominantly male (56.6\%) and had a median age of 32 years (interquartile range, 20-45 years). Chronic obstructive pulmonary disease (COPD; 12.2\%), dyslipidemia (12.1\%), diabetes mellitus (10.4\%), and chronic kidney disease (10.0\%) were the most common comorbidities.

Risk of secondary malignancy according to age, sex, and time interval after transplantation. A total of $43 \mathrm{SM}$ occurred within the observation period (Tables $2 \mathrm{~A}$ and B). The incidence of SM in those receiving HSCT was higher than the incidence of cancers in the general population (SIR 2.00, 95\% CI 1.45-2.69; $P<0.001$ ). Concerning the stem cell type, incidence of cancers in patients receiving allogeneic HSCT was higher than in the normal 
Table 1. Characteristics of patients with haematopoietic stem cell transplantation (HSCT)

\begin{tabular}{|c|c|c|c|}
\hline & Total & Male & Female \\
\hline No. of patients & 2544 & 1439 & 1105 \\
\hline Person-years at risk & 11198 & 6075.6 & 5122.8 \\
\hline Median follow-up, years (interquartile range) & $4.46(2.11-7.75)$ & $4.21(2.00-7.65)$ & $4.82(2.31-8.05)$ \\
\hline Median age, years (interquartile range) & $32(20-45)$ & $32(20-45)$ & $33(20-46)$ \\
\hline \multicolumn{4}{|l|}{ Primary disease } \\
\hline $\begin{array}{l}\text { Acute lymphoblastic leukaemia } \\
\text { Acute myeloid leukaemia } \\
\text { Lymphoma } \\
\text { Multiple myeloma } \\
\text { Severe aplastic anaemia } \\
\text { Thalassaemia } \\
\text { Others }{ }^{\text {a }}\end{array}$ & $\begin{array}{l}293(11.5 \%) \\
867(34.2 \%) \\
678(26.6 \%) \\
270(10.6 \%) \\
270(10.6 \%) \\
68(2.7 \%) \\
98(3.8 \%)\end{array}$ & $\begin{array}{l}167(11.6 \%) \\
458(31.8 \%) \\
390(27.1 \%) \\
172(12.0 \%) \\
162(11.3 \%) \\
30(2.1 \%) \\
60(4.1 \%)\end{array}$ & $\begin{array}{c}126(11.4 \%) \\
409(37.0 \%) \\
288(26.0 \%) \\
98(8.9 \%) \\
108(9.9 \%) \\
38(3.4 \%) \\
38(3.4 \%)\end{array}$ \\
\hline \multicolumn{4}{|l|}{ Treatment } \\
\hline $\begin{array}{l}\text { TBI } \\
\text { Pre-HSCT Radiotherapy } \\
\text { Allogeneic } \\
\text { Autologous }\end{array}$ & $\begin{array}{r}605(23.8 \%) \\
841(33.1 \%) \\
1514(59.5 \%) \\
1030(40.5 \%)\end{array}$ & $\begin{array}{l}335(23.3 \%) \\
469(32.6 \%) \\
836(58.1 \%) \\
603(41.9 \%)\end{array}$ & $\begin{array}{l}270(24.4 \%) \\
372(33.7 \%) \\
678(61.3 \%) \\
427(38.7 \%)\end{array}$ \\
\hline cGVHD & 751 (49.6\%) & $413(49.4 \%)$ & $338(49.8 \%)$ \\
\hline \multicolumn{4}{|l|}{ Immunosupressants ${ }^{b}$} \\
\hline $\begin{array}{l}\text { Cyclosporin } \\
\text { Tacrolimus } \\
\text { Methylprednisolone } \\
\text { Mycophenolate } \\
\text { Sirolimus } \\
\text { Anti-thymocyte globulin } \\
\text { Azathioprine } \\
\text { Cyclophosphamide } \\
\text { Methotrexate }\end{array}$ & $\begin{array}{c}1471(97.1 \%) \\
138(9.1 \%) \\
253(16.7 \%) \\
253(16.7 \%) \\
36(2.3 \%) \\
381(25.1 \%) \\
254(16.7 \%) \\
31(2.0 \%) \\
41(2.7 \%)\end{array}$ & $\begin{array}{c}805(96.2 \%) \\
76(9.1 \%) \\
134(16.0 \%) \\
145(17.3 \%) \\
24(2.8 \%) \\
207(24.7 \%) \\
153(18.3 \%) \\
16(1.9 \%) \\
23(2.7 \%)\end{array}$ & $\begin{array}{c}666(98.2 \%) \\
62(9.1 \%) \\
119(17.5 \%) \\
108(15.9 \%) \\
12(1.7 \%) \\
174(25.6 \%) \\
101(14.8 \%) \\
15(2.2 \%) \\
18(2.6 \%)\end{array}$ \\
\hline \multicolumn{4}{|l|}{ Comorbidities } \\
\hline $\begin{array}{l}\text { Diabetes mellitus } \\
\text { COPD } \\
\text { Chronic kidney disease } \\
\text { Liver cirrhosis } \\
\text { Autoimmune diseases } \\
\text { Dyslipidaemia }\end{array}$ & $\begin{array}{c}265(10.4 \%) \\
311(12.2 \%) \\
255(10.0 \%) \\
48(1.9 \%) \\
152(6.0 \%) \\
309(12.1 \%)\end{array}$ & $\begin{array}{c}162(11.3 \%) \\
195(13.6 \%) \\
159(11.0 \%) \\
27(1.9 \%) \\
67(4.7 \%) \\
135(9.4 \%)\end{array}$ & $\begin{array}{c}103(9.3 \%) \\
116(10.5 \%) \\
96(8.7 \%) \\
21(1.9 \%) \\
85(7.7 \%) \\
174(15.7 \%)\end{array}$ \\
\hline \multicolumn{4}{|l|}{ Age at $\mathrm{HSCT}$, years } \\
\hline $\begin{array}{l}0-19 \\
20-39 \\
40-59 \\
\geqslant 60\end{array}$ & $\begin{array}{r}545(21.4 \%) \\
1027(40.4 \%) \\
871(34.2 \%) \\
101(4.0 \%)\end{array}$ & $\begin{array}{c}302(21.0 \%) \\
567(39.4 \%) \\
508(35.3 \%) \\
62(4.3 \%)\end{array}$ & $\begin{array}{c}243(22.0 \%) \\
460(41.6 \%) \\
363(32.9 \%) \\
39(3.5 \%)\end{array}$ \\
\hline
\end{tabular}

population (SIR 2.77, 95\% CI 1.81-4.05; $P<0.001$ ). The increases were observed in both male (SIR 2.82, 95\% CI 1.54-4.73; $P=0.001$ ) and female patients (SIR 2.71, 95\% CI 1.40-4.73; $P=0.004)$. In patients who received auto-HSCT, however, only males had a higher SIR of SM compared with the general population (SIR 1.89, 95\% CI 1.03-3.17; $P=0.040$ ).

In the sub-analysis by age, the risks of SM were greater for younger patients. For example, those aged 0-19 years after either allo-HSCT (SIR 15.24, 95\% CI 1.85-55.07; $P=0.016$ ) or autoHSCT (SIR 49.91, 95\% CI 1.26-278.07; $P=0.040$ ) had higher risk of SM compared with patients over 60 years who received allo-HSCT (SIR 2.30, 95\% CI $0.28-8.30 ; P=0.433$ ) or autoHSCT (SIR 1.68, 95\% CI 0.55-3.92; $P=0.359$ ). Regarding followup time after transplantation, the risk of SM increased nearly four-fold for patients who were followed for 5-10 years after allo-HSCT $\quad(\mathrm{SIR}=4.56 ; \quad 95 \% \quad \mathrm{CI}=2.55-7.53 ; \quad P<0.001)$ (Table 2A). The cumulative incidence rate of overall SM after HSCT is $0.75 \%(95 \% \mathrm{CI}=0.42-1.34 \%)$ in 5 years and $4.11 \%$ $(95 \% \mathrm{CI}=2.82-5.96 \%)$ in 10 years. The detailed results are outlined in Figure 1.

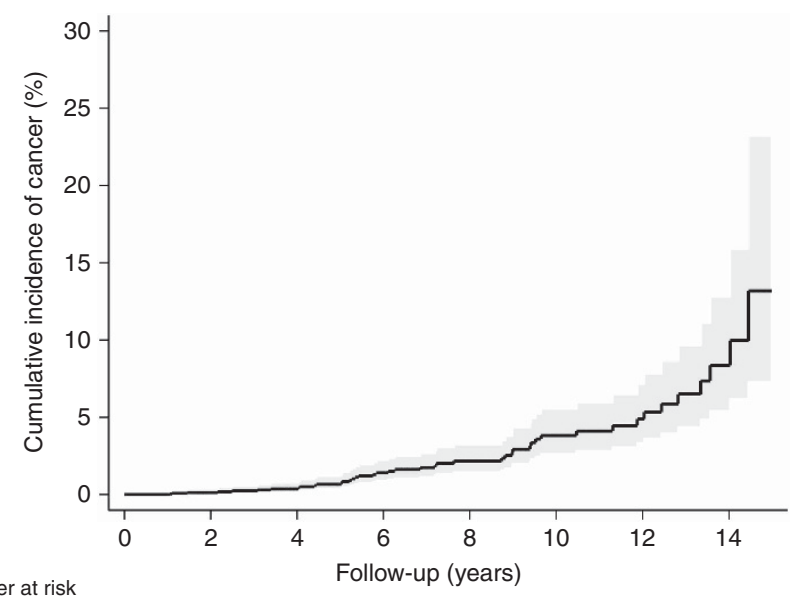

$\begin{array}{lllllllll}\text { HSCT patients } & 2544 & 1962 & 1374 & 947 & 604 & 380 & 215 & 60\end{array}$

Figure 1. The cumulative incidence of secondary cancer in patients with haematopoietic stem cell transplantation. 

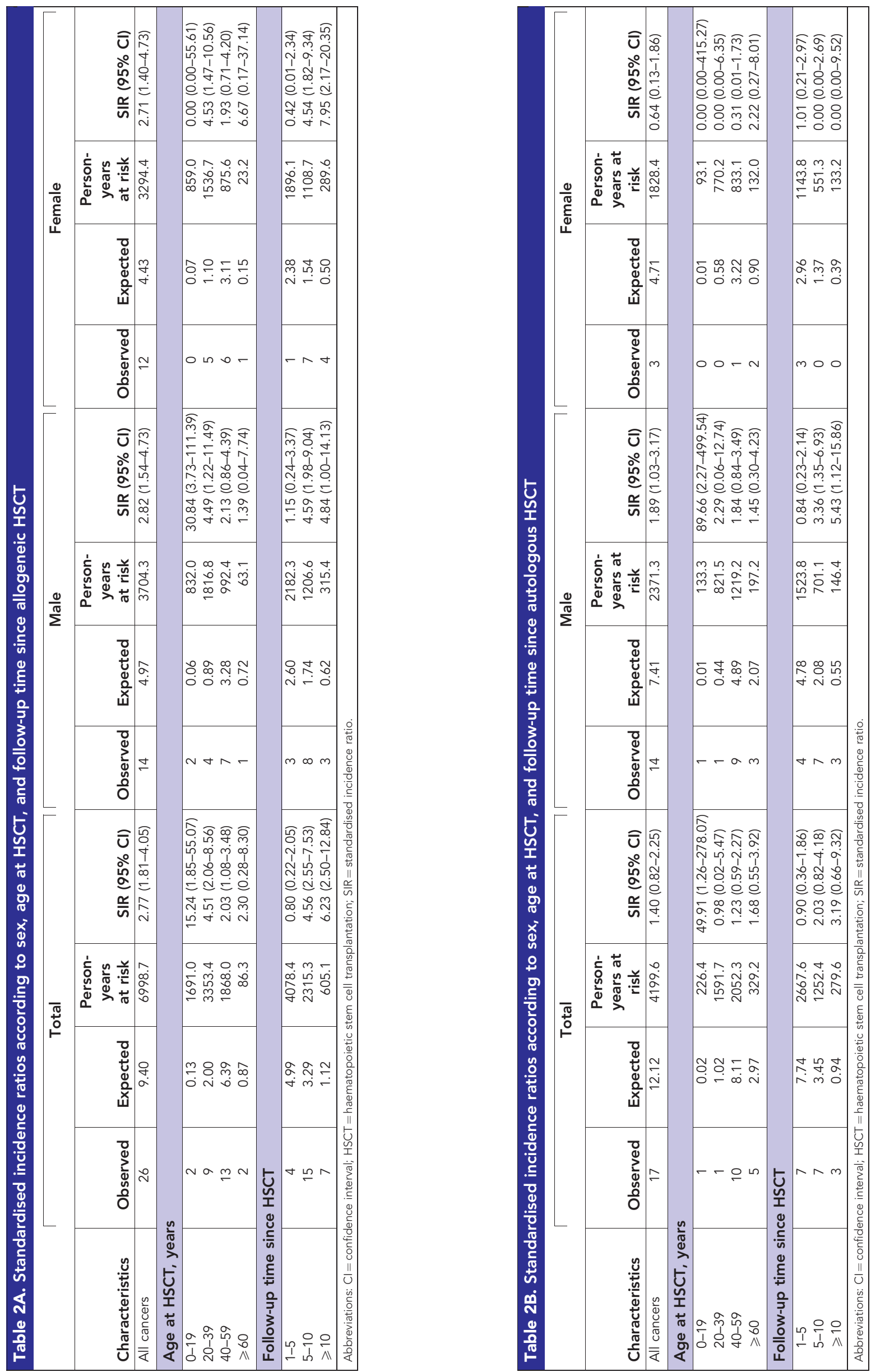
Table 3. Standardised incidence ratios for secondary cancer subtypes among patients with allogeneic HSCT

\begin{tabular}{|c|c|c|c|c|c|c|c|c|c|}
\hline \multirow[b]{2}{*}{ Site of cancers } & \multicolumn{3}{|c|}{ Total } & \multicolumn{3}{|c|}{ Male } & \multicolumn{3}{|c|}{ Female } \\
\hline & Observed & Expected & SIR $(95 \% \mathrm{CI})$ & Observed & Expected & SIR (95\% CI) & Observed & Expected & SIR (95\% CI) \\
\hline All cancers & 26 & 9.40 & $2.77(1.81-4.05)$ & 14 & 4.97 & $2.82(1.54-4.73)$ & 12 & 4.43 & $2.71(1.40-4.73)$ \\
\hline Head and neck & 14 & 1.65 & $8.46(4.63-14.20)$ & 9 & 1.47 & $6.11(2.79-11.60)$ & 5 & 0.18 & $27.59(8.96-64.37)$ \\
\hline $\begin{array}{l}\text { Oral cavity } \\
\text { Pharynx and others }\end{array}$ & $\begin{array}{r}13 \\
1\end{array}$ & $\begin{array}{l}0.92 \\
0.74\end{array}$ & $\begin{array}{c}14.18(7.55-24.25) \\
1.36(0.03-7.55)\end{array}$ & $\begin{array}{l}8 \\
1\end{array}$ & $\begin{array}{l}0.85 \\
0.63\end{array}$ & $\begin{array}{l}9.44(4.08-18.61) \\
1.60(0.04-8.90)\end{array}$ & $\begin{array}{l}5 \\
0\end{array}$ & $\begin{array}{l}0.07 \\
0.11\end{array}$ & $\begin{array}{c}71.94(23.36-167.88) \\
0.00(0.00-33.01)\end{array}$ \\
\hline Digestive & 8 & 2.88 & $2.78(1.20-5.47)$ & 3 & 2.14 & $1.40(0.29-4.09)$ & 5 & 0.74 & $6.78(2.20-15.82)$ \\
\hline $\begin{array}{l}\text { Oesophagus } \\
\text { Stomach } \\
\text { Colon and rectum, Anus } \\
\text { Liver and biliary tract } \\
\text { Pancreas }\end{array}$ & $\begin{array}{l}4 \\
0 \\
1 \\
3 \\
0\end{array}$ & $\begin{array}{l}0.27 \\
0.31 \\
1.05 \\
1.15 \\
0.11\end{array}$ & \begin{tabular}{|c|}
$14.75(4.02-37.76)$ \\
$0.00(0.00-12.01)$ \\
$0.95(0.02-5.32)$ \\
$2.62(0.54-7.64)$ \\
$0.00(0.00-34.43)$
\end{tabular} & $\begin{array}{l}3 \\
0 \\
0 \\
0 \\
0\end{array}$ & $\begin{array}{l}0.26 \\
0.19 \\
0.64 \\
0.97 \\
0.07\end{array}$ & $\begin{array}{c}11.44(2.36-33.42) \\
0.00(0.00-19.21) \\
0.00(0.00-5.74) \\
0.00(0.00-3.79) \\
0.00(0.00-51.50)\end{array}$ & $\begin{array}{l}1 \\
0 \\
1 \\
3 \\
0\end{array}$ & $\begin{array}{l}0.01 \\
0.12 \\
0.40 \\
0.17 \\
0.04\end{array}$ & \begin{tabular}{|c|}
$112.31(2.84-625.78)$ \\
$0.00(0.00-32.07)$ \\
$2.47(0.06-13.76)$ \\
$17.31(3.57-50.58)$ \\
$0.00(0.00-103.82)$ \\
\end{tabular} \\
\hline Lung and mediastinum & 3 & 0.70 & $4.26(0.88-12.44)$ & 1 & 0.44 & $2.26(0.06-12.58)$ & 2 & 0.26 & $7.64(0.93-27.61)$ \\
\hline Bone and Soft tissue & 0 & 0.15 & $0.00(0.00-24.05)$ & 0 & 0.09 & $0.00(0.00-40.57)$ & 0 & 0.06 & $0.00(0.00-59.07)$ \\
\hline Skin & 0 & 0.12 & $0.00(0.00-29.51)$ & 0 & 0.08 & $0.00(0.00-48.96)$ & 0 & 0.05 & $0.00(0.00-74.30)$ \\
\hline Breast & 0 & 1.71 & $0.00(0.00-2.16)$ & 0 & 0.00 & $0.00(0.00-752.49)$ & 0 & 1.70 & $0.00(0.00-2.17)$ \\
\hline Genitourinary & 0 & 1.31 & $0.00(0.00-2.82)$ & 0 & 0.40 & $0.00(0.00-9.28)$ & 0 & 0.91 & $0.00(0.00-4.04)$ \\
\hline Thyroid & 0 & 0.52 & $0.00(0.00-7.04)$ & 0 & 0.12 & $0.00(0.00-31.75)$ & 0 & 0.41 & $0.00(0.00-9.04)$ \\
\hline All others & 1 & 0.34 & $2.95(0.07-16.46)$ & 1 & 0.22 & $4.50(0.11-25.10)$ & 0 & 0.12 & $0.00(0.00-31.66)$ \\
\hline
\end{tabular}

Table 4. Risk factors for secondary cancer development in patients with allogeneic HSCT

\begin{tabular}{|c|c|c|c|c|}
\hline \multirow[b]{2}{*}{ Variables } & \multicolumn{2}{|c|}{ Univariate analysis } & \multicolumn{2}{|c|}{ Multivariate analysis ${ }^{a}$} \\
\hline & $\mathrm{HR}(95 \% \mathrm{Cl})$ & P-value & $\mathrm{HR}(95 \% \mathrm{Cl})$ & P-value \\
\hline Age $\geqslant 40$ & $2.79(1.24-6.27)$ & 0.013 & $2.06(0.85-4.97)$ & 0.109 \\
\hline Sex (male) & $1.04(0.48-2.24)$ & 0.931 & $0.91(0.42-1.99)$ & 0.819 \\
\hline \multicolumn{5}{|l|}{ HSCT } \\
\hline $\begin{array}{l}\text { Malignancies vs. benign } \\
\text { PBSCT vs BMSCT }\end{array}$ & $\begin{array}{l}3.10(0.93-10.32) \\
1.83(0.53-6.29)\end{array}$ & $\begin{array}{l}0.066 \\
0.339\end{array}$ & $2.32(0.68-7.88)$ & 0.178 \\
\hline \multicolumn{5}{|l|}{ Comorbidities } \\
\hline $\begin{array}{l}\text { Diabetes mellitus } \\
\text { COPD } \\
\text { Chronic kidney disease } \\
\text { Liver cirrhosis } \\
\text { Autoimmune diseases } \\
\text { Dyslipidaemia }\end{array}$ & $\begin{array}{c}0.93(0.13-6.86) \\
3.23(1.10-9.48) \\
0.73(0.10-5.41) \\
\text { b } \\
0.98(0.13-7.28) \\
2.73(0.81-9.27)\end{array}$ & $\begin{array}{l}0.940 \\
0.033 \\
0.756 \\
0.989 \\
0.987 \\
0.107\end{array}$ & $2.41(0.78-7.40)$ & 0.126 \\
\hline cGVHD & $2.31(0.97-5.51)$ & 0.058 & $2.19(0.91-5.27)$ & 0.082 \\
\hline \multicolumn{5}{|l|}{ Treatment } \\
\hline $\begin{array}{l}\text { TBI } \\
\text { Pre-HSCT radiotherapy }\end{array}$ & $\begin{array}{l}0.95(0.41-2.18) \\
0.85(0.38-1.90)\end{array}$ & $\begin{array}{l}0.897 \\
0.683\end{array}$ & & \\
\hline \multicolumn{5}{|l|}{ Immunosuppressant $^{c}$} \\
\hline $\begin{array}{l}\text { Cyclosporin } \\
\text { Tacrolimus } \\
\text { Methylprednisolone } \\
\text { Mycophenolate } \\
\text { Sirolimus } \\
\text { Anti-thymocyte globulin } \\
\text { Azathioprine } \\
\text { Cyclophosphamide } \\
\text { Methotrexate }\end{array}$ & $\begin{array}{l}\mathrm{b} \\
2.35(0.70-7.89) \\
1.48(0.62-3.53) \\
0.71(0.17-3.01) \\
5.57(0.74-41.80) \\
0.40(0.05-2.96) \\
3.14(1.44-6.88) \\
1.13(0.34-3.79) \\
1.05(0.36-3.07)\end{array}$ & $\begin{array}{l}0.991 \\
0.166 \\
0.373 \\
0.642 \\
0.095 \\
0.367 \\
0.004 \\
0.841 \\
0.926\end{array}$ & $\begin{array}{l}6.34(0.81-49.29) \\
2.55(1.13-5.77)\end{array}$ & $\begin{array}{l}0.078 \\
0.025\end{array}$ \\
\hline \multicolumn{5}{|c|}{$\begin{array}{l}\text { Abbreviations: } \mathrm{BMSCT}=\text { bone marrow stem cell transplantation; } \mathrm{CGVHD}=\text { chronic graft vs host disease; } \mathrm{Cl}=\text { confidence interval; } \mathrm{COPD}=\text { chronic obstructive pulmonary disease; } \mathrm{HSCT}= \\
\text { haematopoietic stem cell transplantation; } \mathrm{HR}=\text { hazard ratio; } \mathrm{PBSCT}=\text { peripheral blood stem cell transplantation; TBI: total body irradiation. } \\
{ }^{\mathrm{a}} \text { All factors with } \mathrm{P}<0.1 \text { in univariate analyses and sex were included in the Cox multivariate analysis. } \\
\text { b }_{\text {Do not converge. }} \\
\mathrm{c}_{\text {Immunosuppressant was analysed as a time-dependent covariate in the Cox regression model. }}\end{array}$} \\
\hline
\end{tabular}

Specific subtypes of cancers. Among the 26 malignancies that occurred after allo-HSCT, the most commonly observed cancers originated in the head and neck $(n=14)$, the digestive tract $(n=8)$, and the lung or mediastinum $(n=3)$. Compared with the general population, patients who received allo-HSCT had significantly higher SIRs for neoplasms of the oesophagus (SIR 14.75,
95\% CI 4.02-37.76; $P<0.001$ ) and the oral cavity (SIR 14.18, 95\% CI $7.55-24.25 ; \quad P<0.001)$. Regarding gender, women with allo-HSCT were at greater risk of liver and biliary tract malignancies (SIR 17.31, 95\% CI 3.57-50.58; $P=0.001$ ), but this risk was not observed in male patients. Although there was an increased incidence of SM in males receiving auto-HSCT, they did 
Table 5. Cumulative dose of azathioprine for secondary cancer development in patients with allogeneic HSCT

\begin{tabular}{|c|c|c|c|c|}
\hline & \multicolumn{2}{|c|}{ Univariate analysis } & \multicolumn{2}{|c|}{ Multivariate analysis ${ }^{a}$} \\
\hline Variables & HR $(95 \% \mathrm{Cl})$ & $P$-value & $\mathrm{HR}(95 \% \mathrm{Cl})$ & $P$-value \\
\hline \multicolumn{5}{|l|}{ Azathioprine $^{b}$} \\
\hline $\begin{array}{l}\text { Non-use } \\
\quad<15100 \mathrm{mg} \\
\geqslant 15100 \mathrm{mg} \\
\text { Dose-response } \\
\text { relationship }\end{array}$ & $\begin{array}{c}\text { Reference } \\
2.67(0.96-7.40) \\
3.68(1.42-9.51) \\
1.97(1.26-3.09)\end{array}$ & $\begin{array}{l}0.060 \\
0.007 \\
0.003\end{array}$ & \begin{tabular}{c|} 
Reference \\
$2.51(0.90-6.99)$ \\
$3.58(1.37-9.38)$ \\
$1.94(1.22-3.07)$
\end{tabular} & $\begin{array}{l}0.079 \\
0.010 \\
0.005\end{array}$ \\
\hline \multicolumn{5}{|c|}{ 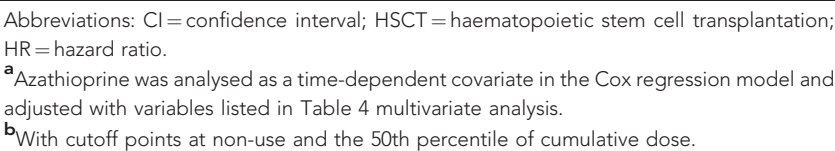 } \\
\hline
\end{tabular}

not appear to be at greater risk for any specific cancer subtypes. Results of these analyses are detailed further in Table 3 and Supplementary Table 1.

Predictors of cancer risk. According to the univariate Cox proportional hazards analysis, the following characteristics increased the risk of SM after allo-HSCT: age $\geqslant 40$ years, HSCT for malignant disease, COPD, cGVHD, and use of the immunosuppressants sirolimus and azathioprine (Table 4). In the multivariate Cox proportional hazards analysis, azathioprine use (HR $2.55,95 \%$ CI $1.13-5.77 ; P=0.025)$ was the only significant risk factor. There were trends for cGVHD (HR 2.19, 95\% CI 0.91-5.27; $P=0.082)$ and sirolimus use (HR 6.34, 95\% CI 0.81-49.29; $P=0.078)$ to be risk factors.

Time-dependent Cox proportional hazard models adjusted for the variables listed in Table 5 were performed to analyse the relationship between azathioprine dose and SM. Using the 50th percentile of cumulative doses as the cutoff point, a cumulative azathioprine dose of $>15100 \mathrm{mg}$ after HSCT significantly increased the risk of SM. Exposure $\geqslant 15100 \mathrm{mg}$ would induce significantly higher risk (HR 3.58, 95\% CI 1.37-9.38; $P=0.01$ ) than those with $<15100 \mathrm{mg}$ (HR 2.51, 95\% CI 0.90-6.99; $P=0.079$ ) in comparison with non-use ones (Table 5). Regarding auto-HSCT, patients who were 40 years or older, male, or had COPD had higher hazard ratios in the univariate analysis (Supplementary Table 2 ), but only age $\geqslant 40$ years was significant for inclusion in the multivariate analysis (HR 3.74, 95\% CI 1.19$11.80 ; P=0.024)$.

Receiving TBI as part of the conditioning regimen did not increase the risk of SM (HR 0.95, 95\% CI 0.41-2.18; $P=0.897$ ) in the univariate analysis of allo-HSCT patients. An analysis tried to explore the association between TBI or cGVHD and various subtypes of SM revealed no association between TBI and any cancer subtype (Supplementary Table 3), but cGVHD was a significant risk factor for head and neck cancer (HR 2.84, 95\% CI 1.02-7.92; $P=0.046$ ) (Supplementary Table 4).

\section{DISCUSSION}

This nationwide population-based study showed that a cohort of 2544 adult patients who received HSCT had an $\sim 2$-fold greater risk of SM compared with the general population. The most common SMs were cancers of the oral cavity and oesophagus in both men and women who received allo-HSCT. The single greatest risk factor for development of SM after allo-HSCT was azathioprine use, which increased the risk of cancer in a dosedependent manner. Although patients under 19 years of age had the highest SIR, patients 40 years or older were at greater risk for developing SM after auto-HSCT.
In Taiwan, both HSCT and cancer are classified under the 'Catastrophic Illness' category by the NHI due to their large associated costs. The NHI has implemented an extremely strict verification process before issuing certification for treatment and requires pathological proof of malignancy or a clinical diagnosis based on laboratory and imaging evidence. Therefore, the diagnosis of malignancies should be accurate and not over- or underestimated. In addition, the NHI defines clear and strict indications for HSCT, as an expensive procedure. Peer review of cases is required to ensure that patient criteria are met. Thus, the diagnoses are reliable and precise.

Several published studies reported an increased risk of developing SM after HSCT (Curtis et al, 1997; Rizzo et al, 2009; Yokota et al, 2012). The risk ratio differs between studies. Curtis et al (1997) reported the risk to be as high as 8.3 times the expected incidence in those surviving $>10$ years after transplantation. A recent study of data from the Center for International Blood and Marrow Transplant Research (CIBMTR) and the Fred Hutchinson Cancer Research Center (FHCRC) database demonstrated that patients developed solid cancers after transplantation at twice the rate expected in the general population (Rizzo et al, 2009). These results are similar to our findings and those reported by Yokota et al (2012) in Japan. Of note, the SIR of SM was higher in young patients and increased with time. Rizzo et al (2009) reported competing risk analyses were $1 \%(95 \% \mathrm{CI} 0.9-1.3 \%)$ at 10 years, $2.2 \%(95 \% \mathrm{CI} 1.7-2.7 \%)$ at 15 years, and $3.3 \%(95 \% \mathrm{CI}$ $2.4-4.5 \%)$ at 20 years after HSCT. Our study also found that the SIR of cancer development after HSCT increased with longer follow-up times.

It is well known that use of immunosuppressants increases the risk of developing a secondary malignancy. Combination use of steroids, azathioprine, and cyclosporine significantly increased the risk of skin cancer after renal transplantation (Bouwes Bavinck et al, 1996). In HSCT, both chronic inflammation from cGVHD and immunosuppressant use may predispose patients to developing secondary malignancies. In 1996, an analysis of 700 patients undergoing HSCT for aplastic anaemia and Fanconi anaemia revealed that azathioprine for CGVHD was a definite risk for solid tumour development after allo-HSCT (Deeg et al, 1996). Another international case-control study identified several major risk factors for the development of squamous cell carcinoma after HSCT, including prolonged azathioprine use, especially when it was combined with cyclosporine and steroids for severe cGVHD (Curtis et al, 2005). The risk ratio was 8.44 (95\% CI 3.17-22.47; $P<0.001)$ in patients receiving cGVHD therapy for $>24$ months. An analysis of different immunosuppressants and therapy duration found that azathioprine, cyclosporine, and steroid therapy for $>12$ months, with or without other therapies, increased the risk of squamous cell carcinoma 38 times (Curtis et al, 2005). However, this study did not mention any association between azathioprine dose and SM.

In our study, a total of 128 patients have been treated with azathioprine in the 751 documented cGVHD patients, and it demonstrated that azathioprine increased SM risk by two-fold, and the risk increased with higher cumulative doses. This finding suggests that not only duration, but also the cumulative dose of azathioprine affects the risk of SM after allo-HSCT. Azathioprine is an oral immunosuppressant that requires metabolic activation into thioguanine nucleotides. These nucleotide analogues (specifically, 6-thioguanine (6-TG)) are incorporated into DNA. DNA containing 6-TG, especially after radiation therapy, is susceptible to mutagenic oxidation and carries a risk of therapy-related cancer in long-term survivors of transplantation (O'Donovan et al, 2005).

Regarding the cancer subtypes of patients with allo-HSCT, the most common SMs are oral cavity tumours (Curtis et al, 2005; Hasegawa et al, 2005; Rizzo et al, 2009; Majhail et al, 2011). However, there are some epidemiological differences between 
Western and Eastern countries. Reports of data from the CIBMTR and FHCRC, which encompass populations in the United States of America and European countries, demonstrated that the sites of SMs, in order of decreasing incidence, were as follows: the oral cavity, liver, brain and central nervous system, and thyroid (Socie et al, 2000; Rizzo et al, 2009). However, our study from Taiwan and another from Japan (Yokota et al, 2012) revealed that in addition to cancers of the oral cavity, oesophageal cancer is also a common SM following allo-HSCT (Hasegawa et al, 2005; Shimada et al, 2005; Chen et al, 2011). This difference may be related to the higher incidence of oesophageal cancer in Asian countries (Warnakulasuriya, 2008; Lin et al, 2013; Zhang, 2013). Another notable difference is skin cancer, which is more frequent in Western countries and usually presents as melanoma rather than squamous or basal cell carcinoma. Skin cancer with melanoma was reported as an excess absolute risk of 1.5 by the CIBMTR and the FHCRC (Rizzo et al, 2009), but squamous or basal cell carcinoma is more common in Asian countries (Hasegawa et al, 2005; Yokota et al, 2012).Our study and the one by Shimada et al (2005) reported that no skin cancer was observed after allo- or autoHSCT.

Use of TBI in HSCT has been described as a major risk factor for SM (Curtis et al, 2005; Friedman et al, 2008). However, our study and others showed no significant association between SM and radiation therapy (Hasegawa et al, 2005; Shimada et al, 2005; Yokota et al, 2012). One explanation for this discrepancy is the smaller proportion of young patients and shorter follow-up time after HSCT in our study. However, other pediatric studies and studies with long follow-up periods also found no association between SM and age or TBI (Baker et al, 2003; Kunkele et al, 2013). Similarly, TBI is associated with increased risk of skin cancers, such as melanoma (Rizzo et al, 2009) and basal or squamous cell carcinoma (Leisenring et al, 2006; Schwartz et al, 2009), but as mentioned above, no skin cancer was observed in our study or a study in Japan (Shimada et al, 2005). This discrepancy requires further investigation and may be the result of ethnic differences.

Another significant risk factor for SM in other studies is cGVHD (Curtis et al, 2005; Rizzo et al, 2009; Majhail, 2011; Majhail et al, 2011).While cGVHD had a hazard ratio of 2.19 for $\mathrm{SM}$ in our study, it was not significant in the multivariate analysis. The lack of statistical significance could be due to small patient number, however, the statistical trend may still implicate cGVHD as an independent risk factor for SM. There were 751 cases of cGVHD in our 1514 patients. This incidence of cGVHD was $\sim 49 \%$, which is higher than in reports from Western countries (Rizzo et al, 2009; Majhail et al, 2011) and another Taiwanese study (Bai et al, 2004). Additional evidence comes from the significant effects of immunosuppressant use. The demand for prolonged use of immunosuppressants reflects the severity and duration of cGVHD. It is possible that in addition to immunosuppressants being a risk factor, cGVHD is, independently or synergistically with immunosuppressants, a risk factor for SM. A previous study also showed that CGVHD and the use of immunosuppressants are independent risks and the occurrence of both factors contributed to higher cancer risk (Curtis et al, 2005). Finally, patients had a much greater risk of SM following allo-HSCT than auto-HSCT, which had only slight increase of risk in male patients. This observation suggests that, in addition to high-dose chemotherapy-induced DNA damage, immunosuppressants (especially azathioprine) and cGVHD are important risk factors for SM.

Our study is limited as a retrospective analysis and NHI database. We were unable to obtain detailed information about severity grading of cGVHD, stage of primary disease, and donorrecipient relationships. However, a multivariate analysis of the CIBMTR database conducted by Curtis et al (1997) revealed that HLA type or familial relationships did not increase the risk of SM
(Rizzo et al, 2009). No information about conditioning regimen was available in our study, but a previous study reported that it did not influence the risk of SM development (Hasegawa et al, 2005). Majhail et al (2011) reported that conditioning with busulfancyclophosphamide increased SM in the oral cavity and other cancers, but that study only focused on busulfan-cyclophosphamide and not on other regimens. The association between the conditioning regimen and SM is still inconclusive and requires more investigation. Many other potential risk factors, such as T-cell depletion and manipulation, anti-thymocyte globulin, and lifestyle characteristics such as smoking or alcohol use, were not available for our analysis. However, these factors did not affect SM development in several previous studies (Curtis et al, 1997, 2005; Hasegawa et al, 2005; Rizzo et al, 2009).

In conclusion, patients receiving HSCT have approximately twice the risk of developing SM than the general population, and this risk increases with time. The incidence of oral and oesophageal cancers in Taiwanese patients significantly increases after alloHSCT. This result is a unique clinical feature that is different from patients in Western countries, where the oesophageal cancer risk is not increased. The use of the immunosuppressant azathioprine, especially with cumulative doses exceeding $15100 \mathrm{mg}$, increases the risk of SM. Taking the autologous transplantation as a reference, our study demonstrates the significant effects of cGVHD and immunosuppressants as the risk of SM. Physicians should be cautious when using azathioprine for GVHD after HSCT. This study suggests that long-term survivors who are treated with HSCT, especially those with risks mentioned above, should be kept under long-term surveillance for early detection of SM.

\section{ACKNOWLEDGEMENTS}

This study is supported by grants from Taipei Veterans General Hospital (V103B-022, V102C-202, and V103E10-001). The study is based in part on data from the National Health Insurance Research Database provided by the Bureau of National Health Insurance, Department of Health and managed by National Health Research Institutes. The interpretation and conclusions contained herein do not represent those of Bureau of National Health Insurance, Department of Health or National Health Research Institutes. Miss Chiu-Mei Yeh contributed significantly to the calculations and interpretations of statistical analyses in this study.

\section{CONFLICT OF INTEREST}

The authors declare no conflict of interest.

\section{REFERENCES}

Bai LY, Chiou TJ, Liu JH, Yen CC, Wang WS, Yan MH, Hsiao LT, Chao TC, Chen PM (2004) Hematopoietic stem cell transplantation for severe aplastic anemia-experience of an institute in Taiwan. Ann Hematol 83(1): 38-43.

Baker KS, DeFor TE, Burns LJ, Ramsay NK, Neglia JP, Robison LL (2003) New malignancies after blood or marrow stem-cell transplantation in children and adults: incidence and risk factors. J Clin Oncol 21(7): 1352-1358.

Bilimoria KY, Chung J, Ju MH, Haut ER, Bentrem DJ, Ko CY, Baker DW (2013) Evaluation of surveillance bias and the validity of the venous thromboembolism quality measure. JAMA 310(14): 1482-1489.

Bouwes Bavinck JN, Hardie DR, Green A, Cutmore S, MacNaught A, O'Sullivan B, Siskind V, Van Der Woude FJ, Hardie IR (1996) The risk of skin cancer in renal transplant recipients in Queensland, Australia. A follow-up study. Transplantation 61(5): 715-721. 
Chen MH, Chang PM, Li WY, Hsiao LT, Hong YC, Liu CY, Gau JP, Liu JH, Chen PM, Chiou TJ, Tzeng CH (2011) High incidence of oral squamous cell carcinoma independent of HPV infection after allogeneic hematopoietic SCT in Taiwan. Bone Marrow Transplant 46(4): 567-572.

Chen PM, Hsiao LT, Chen MH, Chang PM, Liu CY, Hong YC, Tzeng CH, Chiou TJ (2008) Current status of hematopoietic stem cell transplantation in Taiwan. Bone Marrow Transplant 42(Suppl 1): S133-S136.

Chiolero A, Santschi V, Paccaud F (2013) Public health surveillance with electronic medical records: at risk of surveillance bias and overdiagnosis. Eur J Public Health 23(3): 350-351.

Curtis RE, Metayer C, Rizzo JD, Socié G, Sobocinski KA, Flowers MED, Travis WD, Travis LB, Horowitz MM, Deeg HJ (2005) Impact of chronic GVHD therapy on the development of squamous-cell cancers after hematopoietic stem-cell transplantation: an international case-control study. Blood 105(10): 3802-3811.

Curtis RE, Rowlings PA, Deeg HJ, Shriner DA, Socie G, Travis LB, Horowitz MM, Witherspoon RP, Hoover RN, Sobocinski KA, Fraumeni Jr JF, Boice Jr JD (1997) Solid cancers after bone marrow transplantation. $N$ Engl J Med 336(13): 897-904.

Deeg HJ, Socie G, Schoch G, Henry-Amar M, Witherspoon RP, Devergie A, Sullivan KM, Gluckman E, Storb R (1996) Malignancies after marrow transplantation for aplastic anemia and fanconi anemia: a joint Seattle and Paris analysis of results in 700 patients. Blood 87(1): 386-392.

Forrest DL, Nevill TJ, Naiman SC, Le A, Brockington DA, Barnett MJ, Lavoie JC, Nantel SH, Song KW, Shepherd JD, Sutherland HJ, Toze CL, Davis JH, Hogge DE (2003) Second malignancy following high-dose therapy and autologous stem cell transplantation: incidence and risk factor analysis. Bone Marrow Transplant 32(9): 915-923.

Friedman DL, Rovo A, Leisenring W, Locasciulli A, Flowers ME, Tichelli A, Sanders JE, Deeg HJ, Socie G (2008) Increased risk of breast cancer among survivors of allogeneic hematopoietic cell transplantation: a report from the FHCRC and the EBMT-Late Effect Working Party. Blood 111(2): 939-944.

Hasegawa W, Pond GR, Rifkind JT, Messner HA, Lau A, Daly AS, Kiss TL, Kotchetkova N, Galal A, Lipton JH (2005) Long-term follow-up of secondary malignancies in adults after allogeneic bone marrow transplantation. Bone Marrow Transplant 35(1): 51-55.

Kunkele A, Engelhard M, Hauffa BP, Mellies U, Muntjes C, Huer C, Eggert A, Schulte JH, Kremens B (2013) Long-term follow-up of pediatric patients receiving total body irradiation before hematopoietic stem cell transplantation and post-transplant survival of $>2$ years. Pediatr Blood Cancer 60(11): 1792-1797.

La Nasa G, Caocci G, Efficace F, Dessi C, Vacca A, Piras E, Sanna M, Marcias M, Littera R, Carcassi C, Lucarelli G (2013) Long-term health-related quality of life evaluated more than 20 years after hematopoietic stem cell transplantation for thalassemia. Blood 122(13): 2262-2270.

Leisenring W, Friedman DL, Flowers ME, Schwartz JL, Deeg HJ (2006) Nonmelanoma skin and mucosal cancers after hematopoietic cell transplantation. J Clin Oncol 24(7): 1119-1126.
Lin Y, Totsuka Y, He Y, Kikuchi S, Qiao Y, Ueda J, Wei W, Inoue M, Tanaka H (2013) Epidemiology of esophageal cancer in Japan and China. J Epidemiol 23(4): 233-242.

Majhail NS (2011) Secondary cancers following allogeneic haematopoietic cell transplantation in adults. Br J Haematol 154(3): 301-310.

Majhail NS, Brazauskas R, Rizzo JD, Sobecks RM, Wang Z, Horowitz MM, Bolwell B, Wingard JR, Socie G (2011) Secondary solid cancers after allogeneic hematopoietic cell transplantation using busulfancyclophosphamide conditioning. Blood 117(1): 316-322.

O'Donovan P, Perrett CM, Zhang X, Montaner B, Xu YZ, Harwood CA, McGregor JM, Walker SL, Hanaoka F, Karran P (2005) Azathioprine and UVA light generate mutagenic oxidative DNA damage. Science 309(5742): 1871-1874.

Rizzo JD, Curtis RE, Socie G, Sobocinski KA, Gilbert E, Landgren O, Travis LB, Travis WD, Flowers ME, Friedman DL, Horowitz MM, Wingard JR, Deeg HJ (2009) Solid cancers after allogeneic hematopoietic cell transplantation. Blood 113(5): 1175-1183.

Schwartz JL, Kopecky KJ, Mathes RW, Leisenring WM, Friedman DL, Deeg HJ (2009) Basal cell skin cancer after total-body irradiation and hematopoietic cell transplantation. Radiat Res 171(2): 155-163.

Shimada K, Yokozawa T, Atsuta Y, Kohno A, Maruyama F, Yano K, Taji H, Kitaori K, Goto S, Iida H, Morishima Y, Kodera Y, Naoe T, Morishita Y (2005) Solid tumors after hematopoietic stem cell transplantation in Japan: incidence, risk factors and prognosis. Bone Marrow Transplant 36(2): $115-121$.

Socie G, Curtis RE, Deeg HJ, Sobocinski KA, Filipovich AH, Travis LB, Sullivan KM, Rowlings PA, Kingma DW, Banks PM, Travis WD, Witherspoon RP, Sanders J, Jaffe ES, Horowitz MM (2000) New malignant diseases after allogeneic marrow transplantation for childhood acute leukemia. J Clin Oncol 18(2): 348-357.

Warnakulasuriya S (2008) Global epidemiology of oral and oropharyngeal cancer. Oral Oncol 45(4): 309-316.

Wu CY, Chen YJ, Ho HJ, Hsu YC, Kuo KN, Wu MS, Lin JT (2012) Association between nucleoside analogues and risk of hepatitis $B$ virus-related hepatocellular carcinoma recurrence following liver resection. JAMA 308(18): 1906-1914.

Yokota A, Ozawa S, Masanori T, Akiyama H, Ohshima K, Kanda Y, Takahashi S, Mori T, Nakaseko C, Onoda M, Kishi K, Doki N, Aotsuka N, Kanamori H, Maruta A, Sakamaki H, Okamoto S (2012) Secondary solid tumors after allogeneic hematopoietic SCT in Japan. Bone Marrow Transplant 47(1): 95-100.

Zhang Y (2013) Epidemiology of esophageal cancer. World J Gastroenterol 19(34): 5598-5606.

This work is published under the standard license to publish agreement. After 12 months the work will become freely available and the license terms will switch to a Creative Commons AttributionNonCommercial-Share Alike 3.0 Unported License.

Supplementary Information accompanies this paper on British Journal of Cancer website (http://www.nature.com/bjc) 